\title{
Ammonia Detection at Low Temperature by Tungsten Oxide Nanowires ${ }^{+}$
}

\author{
Sandrine Bernardini ${ }^{1, *}$, Florent Pourcin ${ }^{2}$, Nassirou Nambiema ${ }^{1}$, Olivier Margeat ${ }^{2}$, \\ Khalifa Aguir ${ }^{1}$, Christine Videlot-Ackermann ${ }^{2}$, Jörg Ackermann ${ }^{2}$ and \\ Marc Bendahan ${ }^{1}$ \\ 1 Aix Marseille Univ, Université de Toulon, CNRS, IM2NP, Marseille, France; \\ nambiema.nassirou@gmail.com (N.N.); khalifa.aguir@im2np.fr (K.A.); \\ marc.bendahan@im2np.fr (M.B.) \\ 2 Aix Marseille Univ, CNRS, CINaM, Marseille, France; pourcin@cinam.univ-mrs.fr (F.P.); \\ olivier.margeat@univ-amu.fr (O.M.); videlot@cinam.univ-mrs.fr (C.V.-A.); \\ ackermann@cinam.univ-mrs.fr (J.A.) \\ * Correspondence: sandrine.bernardini@im2np.fr; Tel.: +33-491-288-971 \\ † Presented at the Eurosensors 2018 Conference, Graz, Austria, 9-12 September 2018. \\ Published: 10 December 2018
}

\begin{abstract}
Ammonia detection at low temperatures below $150{ }^{\circ} \mathrm{C}$ is attractive to be well suited for flexible substrates in terms of thermal strain and to specific environment not allowing high temperature such as explosive one. In commercial gas sensors, tungsten trioxide is the mostly used semiconducting metal oxide after tin dioxide. We report herein the efficiency of tungsten trioxide nanowires deposited on rigid substrate by drop coating from colloidal solution. This study provides an interesting approach to fabricate ammonia sensors on conformable substrate with significant properties for applications in environmental monitoring devices.
\end{abstract}

Keywords: ammonia; gas sensor; tungsten oxide nanowires; environmental monitoring

\section{Introduction}

Poor air quality is a global concern. Around us, ammonia $\left(\mathrm{NH}_{3}\right)$ is a natural toxic and flammable gas present throughout the atmosphere. It is used in manufacturing of fertilizers, explosives, cleaning fluids and in pharmaceutical applications. It is a colorless gas with a characteristic pungent smell and it can affect environment and human health. The National Institute for Occupational Safety and Health (NIOSH) Recommended Exposure Limit (REL) for ammonia is $25 \mathrm{ppm}\left(18 \mathrm{mg} / \mathrm{m}^{3}\right)$ averaged over an eight-hour workday and a Short Term Exposure Limit (STEL) of $35 \mathrm{ppm}\left(27 \mathrm{mg} / \mathrm{m}^{3}\right)$ during any $15 \mathrm{~min}$ period in the day. Due to these reasons, ammonia monitoring has received considerable attention. Numerous methods have been developed and are in use for ammonia measurement [1]. Since 1962, it has been demonstrated that absorption or desorption of a gas on a metal oxide surface changes the material conductivity [2]. Then, Metal Oxide Semiconductors (MOS) have been applied increasingly as conventional chemical sensing materials because of their simplicity in measurement setup, their miniaturization facility for portable instruments, their high sensitivity and their relatively low cost [3]. Conductometric gas sensor based on $\mathrm{WO}_{3}$ sensing material is demonstrated to respond to $\mathrm{NH}_{3}$ for gas leak detection indoor and outdoor air quality monitoring [4]. Nevertheless, high working temperatures $\left(275-375{ }^{\circ} \mathrm{C}\right)$ and recovery behaviors limit the widespread use of this material. However, when the active layers have a 
large surface area, it means a high surface/volume ratio, the surface adsorbs as much of the target gas as possible and gives a stronger and easily measurable electrical signal [5]. This work aims to investigate the gas-sensing performances of tungsten trioxide $\left(\mathrm{WO}_{3}\right)$ nanowires (NWs) at low temperature.

\section{Materials and Methods}

Our conductometric gas sensor consists of $\mathrm{Ti} / \mathrm{Pt}$ interdigitated electrodes $\quad$ (100 $\mathrm{nm}$ thick and $50 \mu \mathrm{m}$ width, respectively), deposited on $\mathrm{Si} / \mathrm{SiO}_{2}$ by magnetron radiofrequency sputtering and a sensitive $\mathrm{WO}_{3-\mathrm{x}}$ based NWs on the top of them. A heating source can be provided underneath if needed inside the chamber. Ultrathin $\mathrm{WO}_{3-x} \mathrm{NWs}$ were synthesized by a solvothermal method using slight modifications from our previous work [6]. We will briefly remind here. From $110 \mathrm{mg}$ of $\mathrm{Na}_{2} \mathrm{WO}_{4}$ in $3 \mathrm{~mL}$ DI water, and $3 \mathrm{~mL}$ of $7 \% \mathrm{HNO}_{3}$ aqueous solution, a $\mathrm{H}_{2} \mathrm{WO}_{4}$ deposition was formed instantaneously. Then, $16 \mathrm{~mL}$ of oleylamine was added to this $\mathrm{H}_{2} \mathrm{WO}_{4}$ deposition. To get clear solutions, the mixture was sonicated at room temperature for $20 \mathrm{~min}$, transferred into a $45 \mathrm{~mL}$ autoclave, and purged with argon for $15 \mathrm{~min}$. Afterward, the autoclave was put into an electronic oven at $220^{\circ} \mathrm{C}$ during $12 \mathrm{~h}$. The product was then deposited by adding $40 \mathrm{~mL}$ of ethanol and washed twice with absolute ethanol. Then, $10 \mathrm{mg} / \mathrm{mL}$ of the resulting $\mathrm{WO}_{3-\mathrm{x}} \mathrm{NWs}$ were dispersed in toluene. Finally, this solution with the nanomaterials was deposited by drop-casting $10 \mu \mathrm{L}$ of the solutions (about $1 \mathrm{mg} / \mathrm{mL}$ ) onto the electrodes. For this study, $\mathrm{UV} / \mathrm{O}_{3}$ treatment during $15 \mathrm{~min}$ at $80{ }^{\circ} \mathrm{C}$ have been done before and after $\mathrm{WO}_{3-x}$ NWs deposition to remove hydrocarbon contamination on the surface which became more hydrophilic with higher surface tension [7]. To be able to test the sensors up to $130^{\circ} \mathrm{C}$ a heating was performed at $150^{\circ} \mathrm{C}$ during $30 \mathrm{~min}$ on some samples.

Gas sensing investigates was performed at various temperatures under obscurity. A $1 \mathrm{~V}$ DC voltage was applied to the samples while the electrical resistance was monitored using a Keithley Model 2450 Source Meter (Tektronix, USA, Source Measure Unit). As the main purpose was first to check the $\mathrm{WO}_{3-x} \mathrm{NWs}$ gas-sensing properties using $\mathrm{NH}_{3}$ as target gas at low temperature, humidity was avoided using dry air as carrier gas. Because $\mathrm{WO}_{3}$ is n-type semiconductor and $\mathrm{NH}_{3}$ a reduction gas, the sensor response is defined as the following equation:

$$
\mathrm{R}=\mathrm{R}_{\text {dry air }} / \mathrm{R}_{\mathrm{NH}_{3}}
$$

where $\mathrm{R}_{\mathrm{dry}}$ air is the resistance under dry air and $\mathrm{R}_{\mathrm{NH}}$ is the resistance under $\mathrm{NH}_{3}$ exposure.

The measurements have been performed with dry air as both the reference and the carrier gas, maintaining a constant total flow of 500 Standard Cubic Centimeters per Minute (SCCM) via mass flow controllers. The exposition time was fixed at $30 \mathrm{~s}$.

\section{Results and Discussion}

The $\mathrm{WO}_{3-\mathrm{x}} \mathrm{NWs}$ drop casted from a diluted solution on a mesh-coated carbon film presented a homogeneous length (about $100 \mathrm{~nm}$ ) and shape dispersions (Figure 1a) observed by HighResolution Transmission Electron Microscope (HR-TEM) JEOL-JEM 3010 (USA). Figure 1b presents the $\mathrm{WO}_{3-x} \mathrm{NWs}$ homogeneous layer formed on $\mathrm{Si}_{-} \mathrm{SiO}_{2}$ substrate. No response was measurable at $25^{\circ} \mathrm{C}$ and $50^{\circ} \mathrm{C}$ due to the high material resistivity and the high signal/noise ratio. Sensor responses were observed from $75{ }^{\circ} \mathrm{C}$ up to $130^{\circ} \mathrm{C}$ since post-heating process was carry on at $150{ }^{\circ} \mathrm{C}$.

Figure 2 shows the representative dynamic gas response of $\mathrm{WO}_{3-x} \mathrm{NWs}_{\mathrm{s}}$ to $\mathrm{NH}_{3}$ exposure with the concentrations of $2,5,10,20$ and $50 \mathrm{ppm}$ at a working temperature equals to $130{ }^{\circ} \mathrm{C}$. The resistance decrease induced by $\mathrm{NH}_{3}$ exposures on Figure 2 is in agreement with the behavior of a reduction gas on an n-type semiconductor. The mean idea is that the conductivity is controlled by oxygen vacancies which are generated and destroyed at the gaseous interface by reaction with oxygen. 


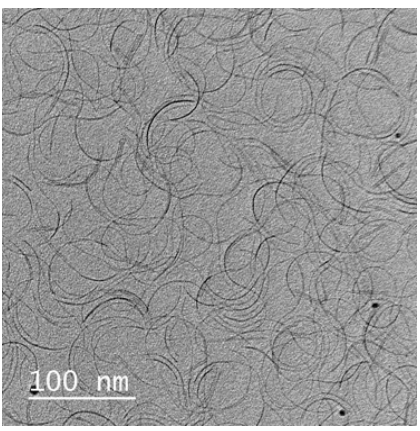

(a)

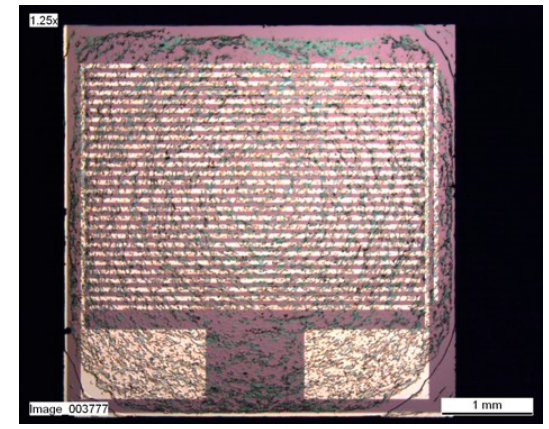

(b)

Figure 1. (a) TEM image of $\mathrm{WO}_{3-\mathrm{x}} \mathrm{NWs}$ and (b) $\mathrm{Si}_{-} \mathrm{SiO}_{2}$ substrate picture with $\mathrm{WO}_{3-\mathrm{x}} \mathrm{NWs}$ dropped on it.

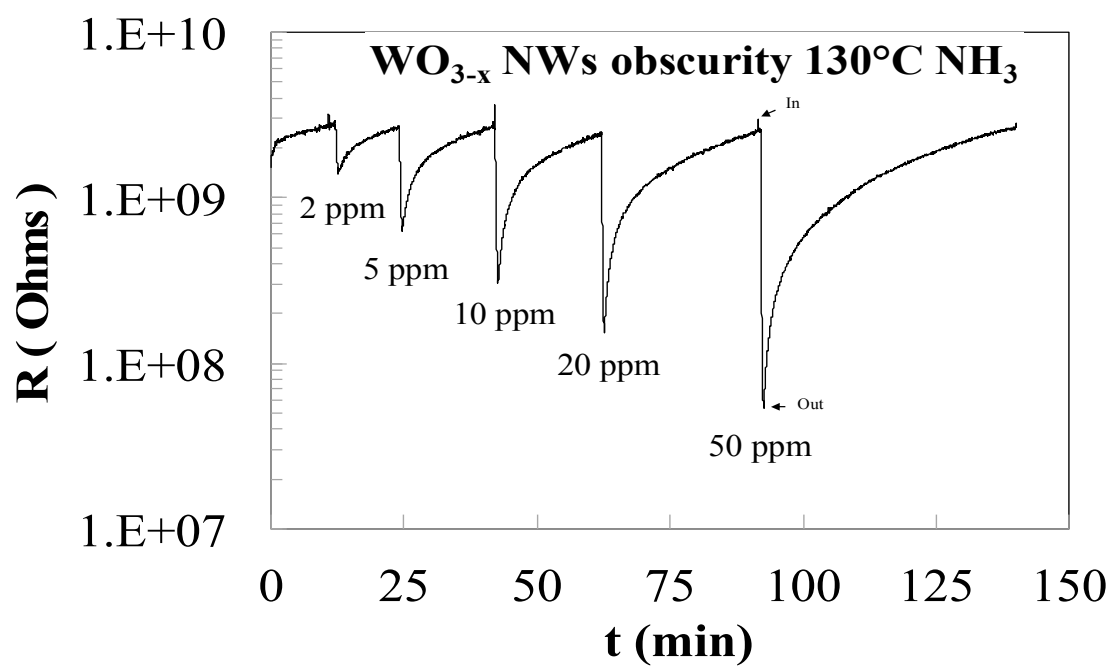

Figure 2. Resistance variation of $\mathrm{WO}_{3-x} \mathrm{NWs}$ with $\mathrm{NH}_{3}$ exposure with the concentrations of 2, 5, 10, 20 and 50 ppm at a working temperature equals to $130{ }^{\circ} \mathrm{C}$.

Before $\mathrm{NH}_{3}$ exposure, oxygen $\left(\mathrm{O}_{2}\right)$ in the air will adsorb and react with $\mathrm{WO}_{3}$ on its interface. The charge carrier concentration and therefore the conductivity change in response to the oxygen vacancy concentration variations at the interface. In this process, $\mathrm{O}^{2}$ will capture electrons from $\mathrm{WO}_{3}$ and transform into negatively-charged species $\left(\mathrm{O}^{\sigma-}=1 / 2,1\right.$ or 2$)$. During $\mathrm{NH}_{3}$ exposure, it will react with $\mathrm{O}^{\sigma-}$ to produce nitrogen or nitrogen oxides and electrons will return to $\mathrm{WO}_{3}$ [8]. The reactions at the interface develop a charge at the interface, which is balanced by a space charge of electrons within the oxide nanowire, near the interface. The surface-to-volume ratio of the nanowires will also increase the conductivity change and sensor sensitivity. The sensor response as a function of the $\mathrm{NH}_{3}$ concentration was plotted in Figure 3.

The response shows a nearly linear increase with the $\mathrm{NH}_{3}$ concentration rise. As illustrated in Figure 3, it was found a fast response less than $20 \mathrm{~s}$ and a time to return to the baseline around $5 \mathrm{~min}$ for an ammonia concentration of $2 \mathrm{ppm}$ at $130^{\circ} \mathrm{C}$. This return time at this low temperature is interesting for using it several times in a short period. According to the sensor response curve presented in Figure 3, the $\mathrm{WO}_{3-x}$ nanowires-based sensing device exhibits good reversible response at $130{ }^{\circ} \mathrm{C}$ without need of light excitation. The repeatability tests, by increasing and decreasing $\mathrm{NH}_{3}$ concentration exposures show a small deviation, an important response, a good reversibility, fast response and recovery without sensor saturation from $2 \mathrm{ppm}$ to $50 \mathrm{ppm} \mathrm{NH}$ gas. 


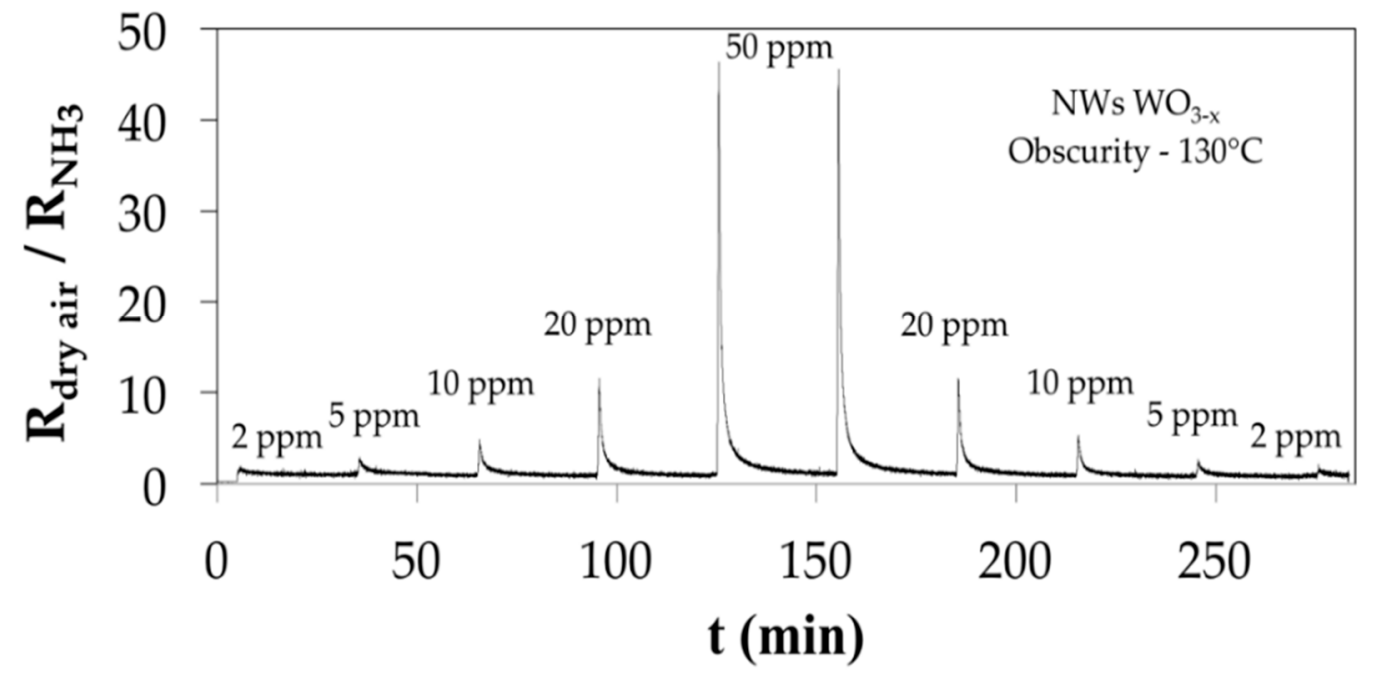

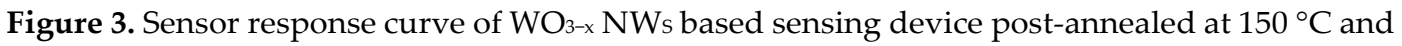
working at $130{ }^{\circ} \mathrm{C}$ in obscurity.

\section{Conclusions}

This study presents the efficiency of tungsten trioxide nanowires WO3-x deposited on rigid substrate by drop coating from colloidal solution to detect ammonia below the Recommended Exposure Limit Values ( $25 \mathrm{ppm}$ ) as low as $2 \mathrm{ppm}$ at $130^{\circ} \mathrm{C}$ without need of light excitation. This working temperature is compatible with thermal strain of flexible substrate. It is an attractive way to fabricate ammonia sensors on flexible substrate with interesting properties in terms of sensitivity and response times for applications in environmental monitoring devices. Further studies will be carry on selectivity versus other environmental gases and light illumination impact.

\section{References}

1. Timmer, B.; Olthuis, W.; Van den Berg, A. Ammonia sensors and their applications-A review. Sens. Actuators B 2005, 107, 666-677, doi:10.1016/j.snb.2004.11.054.

2. Seiyama, T.; Kato, A.; Fujiishi, K.; Nagatani, M. A new detector for gaseous components using semiconductive thin films. Anal. Chem. 1962, 34, 1502-1503, doi:10.1021/ac60191a001.

3. Fine, G. F.; Cavanagh, L.M.; Afonja, A.; Russell, B. Metal oxide semi-conductor gas sensors in environmental monitoring. Sensors 2010, 10, 5469-5502, doi:10.3390/s100605469.

4. Wang, X.; Miura, N.; Yamazoe, N. Study of $\mathrm{WO}_{3}$-based sensing material for $\mathrm{NH}_{3}$ and NO detection. Sens. Actuators B 2000, 66, 74-76, doi:10.1016/S0925-4005(99)00410-4.

5. Wei, W.; Li, W.; Wang, L. High-selective sensitive $\mathrm{NH}_{3}$ gas senor: A density functional theory study. Sens. Actuators B 2018, 502-507, doi:10.1016/j.snb.2018.02.108.

6. Liu, J.; Margeat, O.; Dachraoui, W.; Liu, X.; Fahlman, M.; Ackermann, J. Gram-Scale,Synthesis of Ultrathin Tungsten Oxide Nanowires and their Aspect Ratio-Dependent Photocatalytic Activity. Adv. Funct. Mater. 2014, 24, 6029-6037, doi:10.1002/adfm.201401261.

7. Luo, S.; Wong, C.P. Effect of UV/ozone treatment on surface tension and adhesion in electronic packaging," in IEEE Transactions on Components and Packaging Technologies, 2001, 24, 1, 43-49, doi:10.1109/6144.910801.

8. Jiménez, I.; Centeno, M.A.; Scotti, R.; Morazzoni, F.; Arbiol, J. NH3 interaction with chromium-doped $\mathrm{WO}_{3}$ nanocrystalline powders for gas sensing applications. J. Mater. Chem. 2004, 14, 2412-2420, doi:10.1039/b400872c. 